\title{
Increasing Distributed Generation Using Automatic Voltage Reference Setting Technique
}

\author{
H. Y. Li ${ }^{1}$, MIEEE and H. Leite ${ }^{2}$
}

\begin{abstract}
The increasing connection of distributed energy generation in a distribution network may lead to unacceptable voltage rise. An automatic voltage reference setting technique, acting on the tap change control of the transformer supplying the network, can be used to address this problem. By measuring essential voltage points along the distribution network, an automatic voltage reference setting technique is applied to the Automatic Voltage Control (AVC) relay. The AVC relay then controls an On-Load Tap Changing (OLTC) transformer in order to maximise distributed generation while maintaining the feeder voltage within limits. The automatic voltage reference setting technique and its implementation are described. A closed-loop testing facility, based on a Real Time Digital Simulator (RTDS), was constructed and used to test the technique. The paper presents and discusses the results obtained and shows how this technique may be used to maximise the distributed generation that can be connected to a distribution feeder.
\end{abstract}

Index Terms - Distributed generation, voltage regulation, AVC relay, automatic voltage reference setting algorithm.

\section{I- INTRODUCTION}

C ONCERN over global climate change in many countries has led to governments supporting the use of renewable energy. Elsewhere, distributed resources are used increasingly to provide local power supplies where there are transmission or distribution constraints. This means that a growing capacity of Distributed Generation (DG) is being connected to distribution networks with considerable effects on distribution network voltage regulation $[1,2]$.

Historically, electrical energy is supplied from transmission networks to customers via distribution feeders. Voltage control in a distribution feeder often employs an Automatic Voltage Control (AVC) relay [3] and On-Load Tap Changing (OLTC) transformers [4,5]. The highest voltage along the feeder is generally at the sending-end busbar and the voltage along the feeder gradually reduces due to line impedance and loads. Commercially available AVC relays [3] generally use only the sending-end busbar voltage and sometimes current measurements for line-drop compensation algorithms [6].

If DG is connected to a distribution feeder, the voltage may rise at the point where the generator is connected. Due to the

\footnotetext{
${ }^{1}$ Dr. Haiyu $\mathrm{Li}$ is with the Electrical Energy and Power Systems Group, the School of Electrical and Electronics Engineering, The University of Manchester (formerly UMIST), P.O. BOX 88, Manchester, M60 1QD, U.K.

${ }^{2}$ Dr. Helder Leite is with University of Porto, Portugal, hleite@fe.up.pt
}

changes in DG power flow and even reverse power flow, the feeder currents no longer remain proportional to load currents. Line drop compensation methods are thus inadequate once DG is connected to a distribution feeder [6]. Some voltage control methods for the connection of a limited capacity of DGs on distribution feeders have been investigated [7, 8]. However, these techniques use only the local voltage and current measurements and no action is taken to control the voltage rise or drop caused by DGs. The capacity of DGs that may be connected to a distribution feeder without causing over voltages is limited [9]. Volt-var co-ordination control of OLTC transformers, voltage regulators and capacitor banks has also been reported [10]. However var management in the $\mathrm{UK}$, as a mean of reducing the voltage fluctuations in distribution networks, has not yet been supported by appropriate pricing mechanisms [11].

This paper describes an Automatic Voltage Reference Setting (AVRS) technique that provides a voltage reference setting for existing AVC relays and OLTC transformers to maximise the DG that may be connected to the feeders. The AVRS technique measures two or more essential voltages along multiple feeders. The maximum and minimum voltages from the voltage measurements are selected and compared to the feeder voltage limits. The results are then used to determine a new voltage reference for the AVC relay. The paper then shows how the technique can be used to maximise the DG that may be connected to a realistic multiple feeders network. Experimental results using a Real Time Digital Simulator (RTDS) are presented.

\section{II- Principle of Automatic voltage Reference SETTING TECHNIQUE}

\subsection{Feeder voltage profile changes}

When considering the operation of DG in a distribution system, the feeder voltage profiles will depend on DG power, loads and line impedance. The distribution feeder shown in Fig. 1 is used to illustrate the effect of DG on voltage profiles.

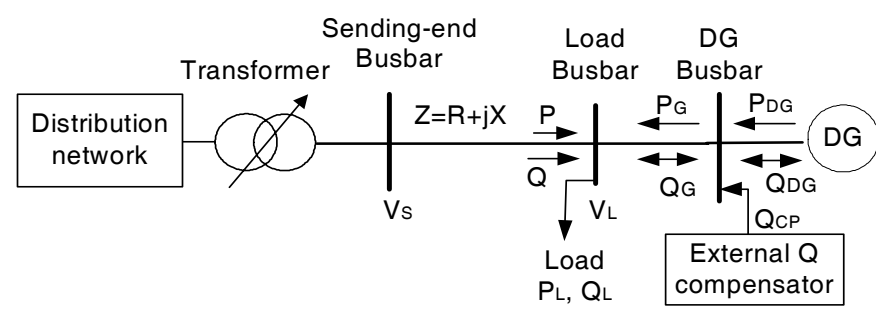

Fig.1 A simplified distribution feeder connected to one DG 
In Fig. $1 \mathrm{~V}_{\mathrm{S}}$ is the sending-end busbar voltage, $\mathrm{Z}(\mathrm{R}+\mathrm{j} \mathrm{X})$ is the line impedance and $\mathrm{V}_{\mathrm{L}}$ is the load busbar voltage. The voltage difference between $\mathrm{V}_{\mathrm{S}}$ and $\mathrm{V}_{\mathrm{L}}$ can be written as:

$$
\overline{\mathrm{V}}_{S}=\overline{\mathrm{V}}_{L}+(R+j X)\left(\frac{\mathrm{P}-\mathrm{jQ}}{\overline{\mathrm{V}}_{\mathrm{L}}^{*}}\right)
$$

where $\mathrm{P}=-\mathrm{P}_{\mathrm{G}}+\mathrm{P}_{\mathrm{L}}$ and $\mathrm{Q}= \pm \mathrm{Q}_{\mathrm{G}}+\mathrm{Q}_{\mathrm{L}}$. Considering $\overline{\mathrm{V}}_{\mathrm{L}}$ as the voltage reference with zero angle, i.e. $\overline{\mathrm{V}}_{\mathrm{L}}=\mathrm{V}_{\mathrm{L}} \angle 0^{\circ}$, equation (1) becomes:

$\overline{\mathrm{V}}_{\mathrm{S}}=\mathrm{V}_{\mathrm{L}}+\frac{\mathrm{RP}+\mathrm{XQ}}{\mathrm{V}_{\mathrm{L}}}-\mathrm{j} \frac{\mathrm{XP}-\mathrm{RQ}}{\mathrm{V}_{\mathrm{L}}}$

For a distribution overhead line, the ohmic value of $\mathrm{R}$ is close to the ohmic value of $\mathrm{X}$ and the imaginary part of $\mathrm{j} \frac{\mathrm{XP}-\mathrm{RQ}}{\mathrm{V}_{\mathrm{L}}}$ is normally small [1]. Since the real part in equation (2) is much greater than the imaginary part, only the real part in equation (2) may be considered. Equation (2) may then be approximately rewritten as:

$$
\mathrm{V}_{\mathrm{L}} \approx \mathrm{V}_{S}-\frac{\mathrm{PR}+\mathrm{QX}}{\mathrm{V}_{\mathrm{L}}}
$$

In a lightly-loaded circuit, the $\operatorname{load} \mathrm{P}_{\mathrm{L}}$ and $\mathrm{Q}_{\mathrm{L}}$ local to the generator is small. DG var injection into the distribution network is not considered to be useful in UK [11], so the reactive power injected into the feeder can be controlled either by the excitation of a synchronous generator or by using external reactive compensation in order to keep $\mathrm{Q}_{\mathrm{G}}$ at zero. If the current from the generator is at unity power factor, the generator $\mathrm{Q}_{\mathrm{G}}=0$, and the local load $\mathrm{P}_{\mathrm{L}}$ and $\mathrm{Q}_{\mathrm{L}}$ are ignored, then $\mathrm{P} \approx-\mathrm{P}_{\mathrm{G}}, \mathrm{Q} \approx 0$ and the feeder voltage rise is given by:

$$
\mathrm{V}_{\mathrm{L}} \approx \mathrm{V}_{\mathrm{S}}+\frac{\mathrm{P}_{\mathrm{G}} \mathrm{R}}{\mathrm{V}_{\mathrm{L}}}
$$

Equation (4) shows that $\mathrm{V}_{\mathrm{L}}$ is higher than $\mathrm{V}_{\mathrm{S}}$ due to the $\mathrm{DG}$ active power injected into the feeder. Maximum injected power from the generator can be obtained by reducing the sending-end busbar voltage to just above the minimum allowed voltage (Fig. 2). However, if the generator is out of service at a time of heavy load then the feeder voltage will drop below the minimum permitted value. Hence, dynamic control of the sending-end busbar voltage is required.

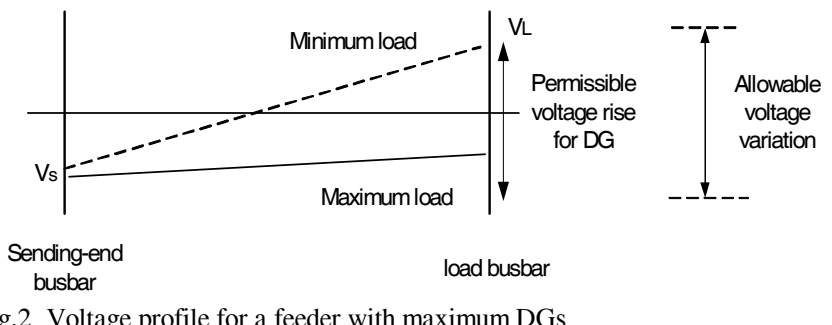

Fig.2 Voltage profile for a feeder with maximum DGs

\subsection{Automatic voltage reference setting technique}

The arrangement of a feeder voltage control system incorporating with the proposed Automatic Voltage Reference Setting (AVRS) device is shown in Fig.3.
The voltage control system consists of an OLTC transformer, an AVC relay and an AVRS device. The AVC relay measures the local busbar voltage, $V_{S}$, and then compares it with a pre-set voltage reference, $\mathrm{V}_{\text {pre-ref, }}$ to determine whether the OLTC transformer should tap or not. Since the AVC relay only measures the local voltage $V_{s}$, it does not know the voltage anywhere else on the feeder.

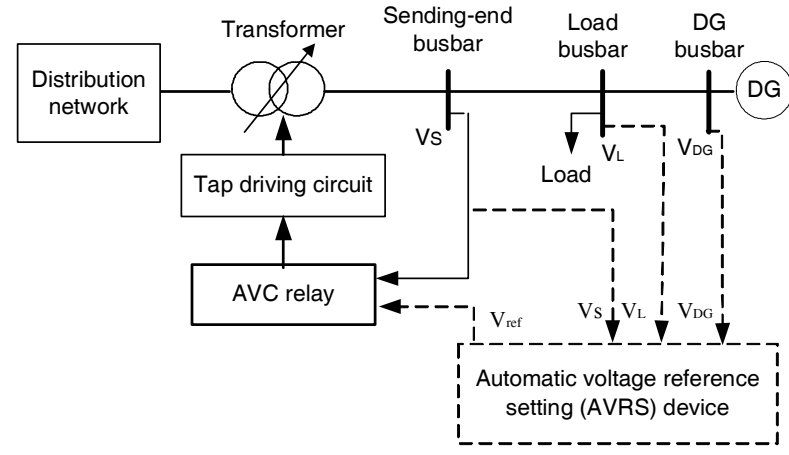

Fig.3 A basic feeder voltage control system with AVRS

The function of the AVRS device is to determine a voltage reference, $V_{\text {ref }}$, for the AVC relay according to the local voltage, $\mathrm{V}_{\mathrm{s}}$, and all essential remote voltage measurements. The AVC relay's voltage reference setting may be given by:

$\mathrm{V}_{\text {ref }}($ new $)=\mathrm{V}_{\text {ref }}+f\left(\mathrm{~V}_{\text {ref }}, \mathrm{V}_{\text {up_limit }}, \mathrm{V}_{\text {low_limit }}, \mathrm{V}_{1} \ldots \mathrm{V}_{\mathrm{m}}\right)$

$f\left(\mathrm{~V}_{\text {ref }}, \mathrm{V}_{\text {up_limit }}, \mathrm{V}_{\text {low_limit }}, \mathrm{V}_{1} \ldots \mathrm{V}_{\mathrm{m}}\right)=$

$\begin{cases}=0 & \text { if } \forall\left(V_{1} \ldots \mathrm{V}_{\mathrm{m}}\right)<\mathrm{V}_{\text {up_limit }} \wedge \forall\left(V_{1} \ldots \mathrm{V}_{\mathrm{m}}\right)>\mathrm{V}_{\text {low_limit }} \\ =\Delta V & \text { if } \forall\left(V_{1} \ldots \mathrm{V}_{\mathrm{m}}\right)>\mathrm{V}_{\text {up_limit }} \wedge \forall\left(V_{1} \ldots \mathrm{V}_{\mathrm{m}}\right)>\mathrm{V}_{\text {low_limit }} \\ =-\Delta V & \text { if } \forall\left(V_{1} \ldots \mathrm{V}_{\mathrm{m}}\right)<\mathrm{V}_{\text {up_limit }} \wedge \forall\left(V_{1} \ldots \mathrm{V}_{\mathrm{m}}\right)<\mathrm{V}_{\text {low_limit }} \\ =\text { Alarm } & \text { if } \forall\left(V_{1} \ldots \mathrm{V}_{\mathrm{m}}\right)>\mathrm{V}_{\text {up_limit }} \wedge \forall\left(V_{1} \ldots \mathrm{V}_{\mathrm{m}}\right)<\mathrm{V}_{\text {low_limit }}\end{cases}$

Where $\mathrm{V}_{\text {ref }}(\mathrm{k}+1)$ is the new voltage reference setting for the AVC relay, $\mathrm{V}_{\text {ref }}(\mathrm{k})$ is the AVC relay's current voltage reference setting, $f$ is a function of $\mathrm{V}_{\text {ref }}(\mathrm{k})$, the feeder voltage upper limit $\left(\mathrm{V}_{\mathrm{f} \text {-upper }}\right)$, the feeder voltage lower limit $\left(\mathrm{V}_{\mathrm{f} \text {-lower }}\right)$, the local voltage measurement $\left(\mathrm{V}_{\mathrm{s}}\right)$ and ' $\mathrm{m}$ ' essential remote voltage measurements $\left(\mathrm{V}_{1}, \ldots \mathrm{V}_{\mathrm{m}}\right)$. The ' $\mathrm{m}$ ' essential remote voltage measurements include all the points where either the maximum or the minimum voltage are most likely to occur under the various network load and multiple distributed generation conditions. They may be determined through load flow studies by adding load uncertainty errors up to $\pm 50 \%$ on the maximum and minimum load conditions.

For the basic feeder in Fig.3, two essential remote voltage measurement points $\mathrm{V}_{\mathrm{DG}}$ and $\mathrm{V}_{\mathrm{L}}$ were identified. $\mathrm{V}_{\mathrm{DG}}$ is the most likely voltage point to experience maximum voltage on the feeder and $\mathrm{V}_{\mathrm{L}}$ at the load centre is the most likely minimum voltage point on the feeder.

The flow chart of the AVRS algorithm is described in Fig.4, where the AVRS algorithm only selects the maximum voltage, 
$\mathrm{V}_{\max }$, and the minimum voltage, $\mathrm{V}_{\min }$, among the local voltage $\mathrm{Vs}$ and all ' $\mathrm{m}$ ' essential remote voltage measurements. $V_{\max }$ and $\mathrm{V}_{\min }$ are then compared to the feeder voltage limits. If $\mathrm{V}_{\text {max }}$ exceeds $\mathrm{V}_{\mathrm{f} \text {-upper }}$ and also $\mathrm{V}_{\text {min }}$ falls below $\mathrm{V}_{\text {f-lower }}$, it is not possible for the voltage control system to regulate the feeder, the algorithm thus exits the loop immediately and may send an alarm signal to the utility control centre. If both $\mathrm{V}_{\max }$ and $\mathrm{V}_{\text {min }}$ are within the feeder limits, the function of $f$ in equation (5) will calculate either $+\Delta \mathrm{V}$ or $-\Delta \mathrm{V}$ according to the selected ' $\mathrm{m}$ ' essential remote voltage measurements, so that a new voltage reference setting, $\mathrm{V}_{\text {ref }}(\mathrm{k}+1)$, is obtained. The algorithm can be reset to the pre-set $\mathrm{V}_{\text {pre-ref, }}$, i.e. $\mathrm{V}_{\text {ref }}(\mathrm{k}+1)=\mathrm{V}_{\text {pre-ref }}$, in case of failure of the AVRS device.

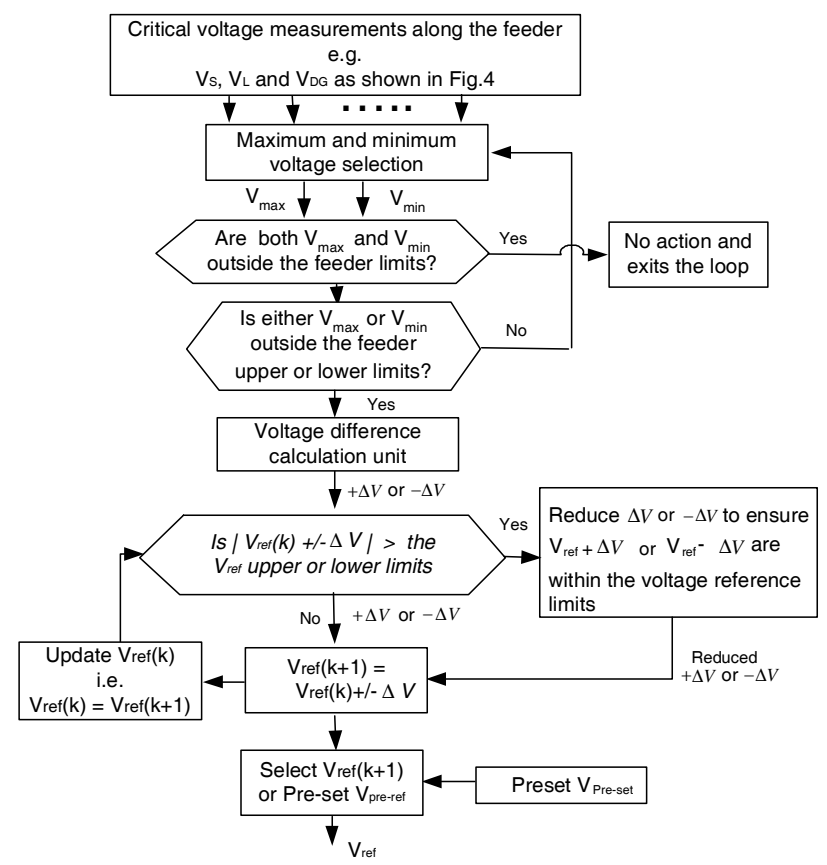

Fig. 4 The flow chart of the AVRS algorithm

\section{III- EVALUATION USING PSCAD/EMTDC}

\subsection{Feeder configuration}

The $11 \mathrm{kV}$ distribution network shown in Fig.5 is one of the UK regional distribution networks. It was modelled using PSCAD/EMTDC to evaluate the AVRS technique.

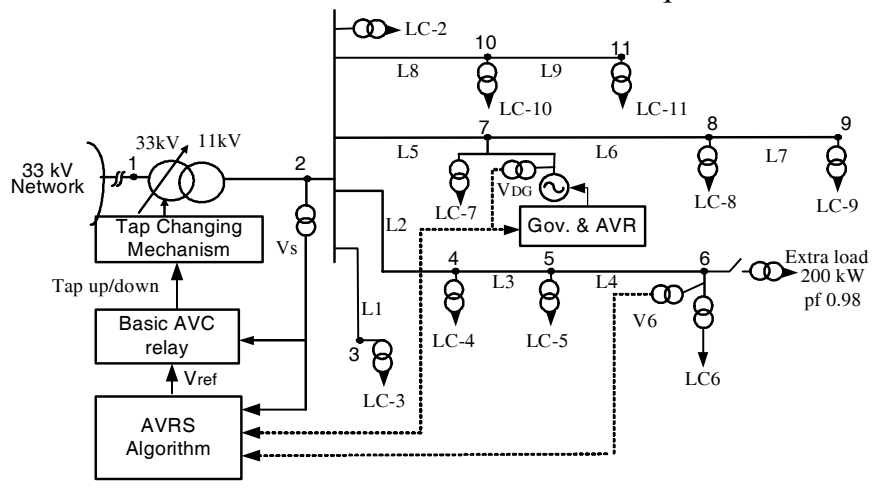

Where: LC:- Load centre, L-Line, DG:- Distributed generation AVRS: - Automatic voltage reference setting

Fig. 5 Radial distribution feeder with OLTC, AVC relay and AVRS device
The network model included a $33 \mathrm{kV}$ network source, a 33/11kV OLTC transformer, 5 feeders, 11 load centres, an AVC relay, an AVRS algorithm and one distributed synchronous generator. The $33 \mathrm{kV}$ network source has a short circuit level of $750 \mathrm{MVA}$ and the $\mathrm{X} / \mathrm{R}$ ratio is 10 . The transformer model is rated at 5MVA with $8.5 \%$ reactance. It has 15 tap change intervals with the voltages from $28.05 \mathrm{kV}$ to $34.65 \mathrm{kV}$ at a tap step of $1.43 \%$. The AVC relay was modelled based on the MicroTapp AVC relay specification [3]. Thus four voltage reference setting targets $0,1,3$ and 4 were set at $11.44 \mathrm{kV}(104 \%$ of $11 \mathrm{kV}), 11.165 \mathrm{kV}(101.5 \%$ of $11 \mathrm{kV})$, $10.89 \mathrm{kV}(99 \%$ of $11 \mathrm{kV})$ and $10.615(96.5 \%$ of $11 \mathrm{kV})$ respectively. The AVC relay deadband was $+2.5 \%$ of $11 \mathrm{kV}$. Line impedances of L1 to L9, and load conditions of load centre 2 to 11 are given in Appendix. Based on off-line load flow studies by adding load uncertainty errors up to $\pm 50 \%$ on the minimum and maximum load conditions (see Appendix), three essential voltage measurements were identified. They were the feeder sending-end voltage, $\mathrm{V}_{\mathrm{S}}$, the generator busbar voltage, $\mathrm{V}_{\mathrm{DG}}$ and the load centre 6 voltage, $\mathrm{V}_{6}$. Evaluations of the feeder voltage control system with the AVRS algorithm were performed.

\subsection{Evaluation of AVC relay and AVRS algorithm}

At the moment in the $\mathrm{UK}$, the $11 \mathrm{kV}$ feeder voltage upper limit, $\mathrm{V}_{\mathrm{f} \text {-upper, }}$ is $11.66 \mathrm{kV}(11 \mathrm{kV}+6 \%)$, the lower limit, $\mathrm{V}_{\mathrm{f} \text {-lower }}$, is $10.34 \mathrm{kV}(11 \mathrm{kV}-6 \%)$, the generator connection point voltage

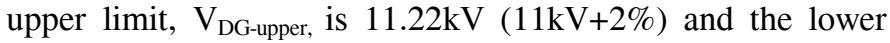
limit, $\mathrm{V}_{\text {DG-lower, }}$ is $10.34 \mathrm{kV} \quad(11 \mathrm{kV}-6 \%) \quad$ [12]. Since PSCAD/EMTDC is a power system transient simulation tool, all the power system components are modelled in detail and the simulation time step must be set at $\mu$ s time scale. To simulate the model of Fig. 5 with a $20 \mu$ s time step for 10 seconds would take 9-10 minutes. To speed up the simulation, the time for all case studies was scaled down in seconds. For the AVC relay model, the initial time delay was thus set at $4 \mathrm{~s}$ and the inter-tap delay was set at $2 \mathrm{~s}$.

\section{Case 1: Voltage profiles under maximum load condition}

This is the case that maximum load centre 2 to 11 in Fig.5 were considered (see Appendix). Initially $V_{\text {ref }}$ of the AVC relay was set at $11.165 \mathrm{kV}$ and the DG power output started from zero and then increased with unity power factor control. The feeder voltage profiles in responding to the change of DG power are shown in Fig.6. The power contributions from the substation and the DG are shown in Fig.7.

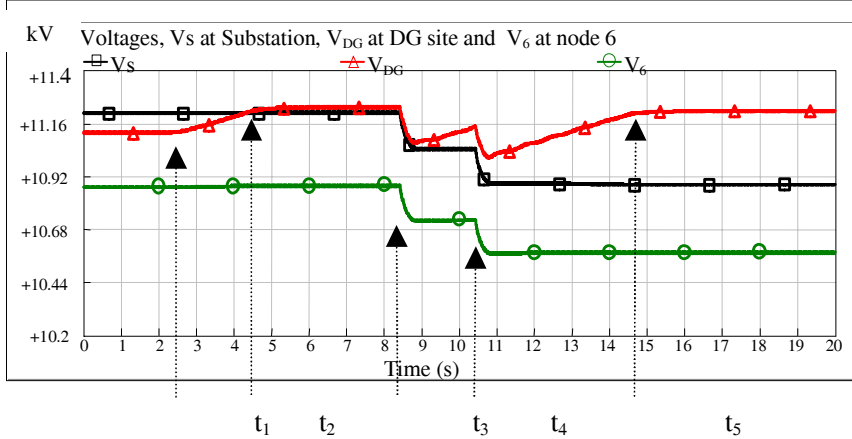

Fig.6 Feeder voltages without AVRS algorithm during the change of DG power output and light load condition 


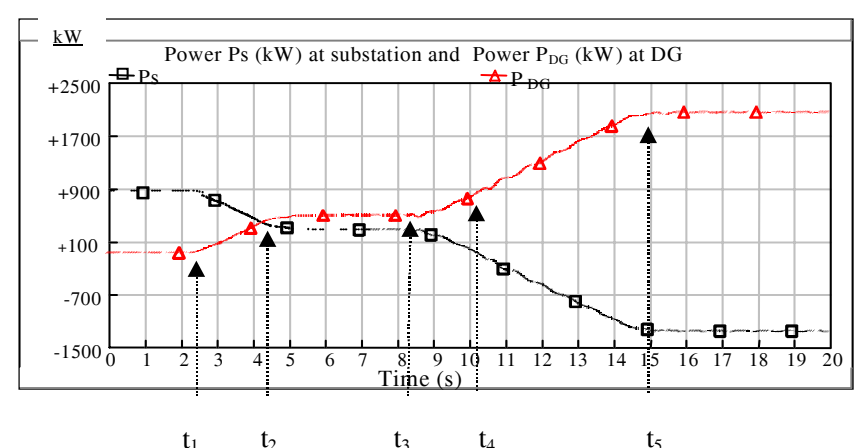

Fig.7 Active power contributions from the substation and the DG

From Fig.6 and Fig.7, it can been seen that when the DG power output was zero between $0 \mathrm{~s}$ and $\mathrm{t}_{1}(2.2 \mathrm{~s}), \mathrm{V}_{\mathrm{DG}}$ (the hollow triangle symbol) of $11.13 \mathrm{kV}$ was below the DG connection point voltage upper limit $\left(\mathrm{V}_{\mathrm{DG}-\text {-upper }}\right), \mathrm{V}_{\mathrm{s}}$ (the hollow square symbol) of $11.19 \mathrm{kV}$ and $\mathrm{V}_{6}$ (the hollow cycle symbol) of $10.89 \mathrm{kV}$ were within the feeder upper and lower limits. The DG started to output power at $t_{1}(2.2 \mathrm{~s})$. When the DG increased its power to $430 \mathrm{~kW}$ at $\mathrm{t}_{2}(4.3 \mathrm{~s})$, it caused $\mathrm{V}_{\mathrm{DG}}$ to exceed $\mathrm{V}_{\text {DG-upper }}$, at $\mathrm{t}_{2}$, but $\mathrm{Vs}$ and $\mathrm{V}_{6}$ had not changed. As $\mathrm{Vs}$ had not changed, the AVC relay did not send a tap changing command to the OLTC transformer. However when the AVRS algorithm detected $\mathrm{V}_{\mathrm{DG}}$ exceeding $\mathrm{V}_{\text {DG-upper }}$ at $\mathrm{t}_{2}$, it waited a pre-set time of 4s. At $t_{3}(8.3 \mathrm{~s})$, the AVRS algorithm changed $\mathrm{V}_{\text {ref }}$ from $11.165 \mathrm{kV}$ to $10.89 \mathrm{kV}$ and the AVC relay instructed the OLTC transformer to tap down immediately. This brought $\mathrm{V}_{\mathrm{S}}$ down from $11.19 \mathrm{kV}$ to $11.0275 \mathrm{kV}$. Since $\mathrm{V}_{\mathrm{S}}$ of $11.0275 \mathrm{kV}$ was still outside of the AVC relay deadband, the AVC relay waited $2 \mathrm{~s}$ of inter-tap delay and then instructed the OLTC transformer to change another tap down at $\mathrm{t}_{4}(10.3 \mathrm{~s})$. $\mathrm{V}_{\mathrm{S}}$ was thus changed from $11.028 \mathrm{kV}$ to $10.9 \mathrm{kV}$ and $\mathrm{V}_{\mathrm{DG}}$ from $11.16 \mathrm{kV}$ to $11.07 \mathrm{kV}$. Since $\mathrm{V}_{\mathrm{DG}}$ of $10.97 \mathrm{kV}$ at $\mathrm{t}_{4}$ was lower than $\mathrm{V}_{\text {DG-upper, }}$, the $\mathrm{DG}$ was allowed to output more power increasing from $450 \mathrm{~kW}$ at $\mathrm{t}_{4}$ to $2100 \mathrm{~kW}$ at $\mathrm{t} 5(15 \mathrm{~s})$. At t5 (15s) $\mathrm{V}_{\mathrm{DG}}$ increased from $11.07 \mathrm{kV}$ to $11.21 \mathrm{kV}$.

\section{Case 2: Voltage profiles under minimum load condition}

In this case, the minimum load centres 2 to 11 in Fig.5 were considered (see Appendix). The feeder voltage profiles in responding to the change of DG power are shown in Fig.8. The power contributions from the substation and the DG are shown in Fig.9.

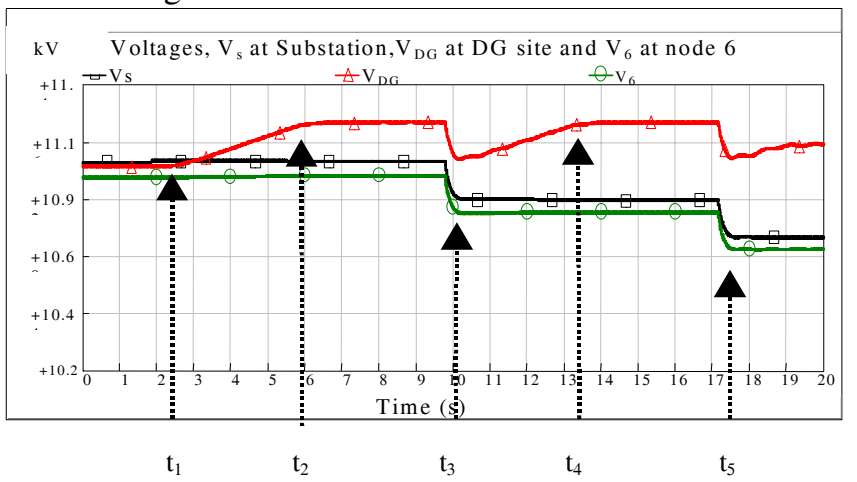

Fig.8 Feeder voltages with AVRS algorithm during the change of DG power output and light load condition

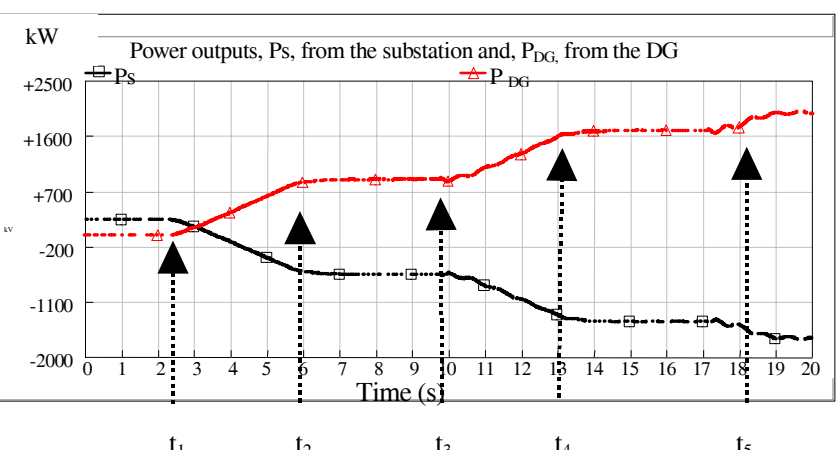

Fig.9 Active power contributions from the substation and the DG

For the estimated minimum load condition, $\mathrm{V}_{\text {ref }}$ was initially also set at $11.165 \mathrm{kV}$ and the DG power output was started from zero and gradually increased with unity power factor control. When DG power output was zero between $0 \mathrm{~s}$ and $\mathrm{t}_{1}$ (2.2s) (shown in Fig.9), from Fig.8 $\mathrm{V}_{\mathrm{DG}}$ (the hollow triangle symbol) of $10.99 \mathrm{kV}$ was below the DG $\mathrm{V}_{\text {DG-upper, }}, \mathrm{V}_{\mathrm{s}}$ (the hollow square symbol) of $10.97 \mathrm{kV}$ and $\mathrm{V}_{6}$ (the hollow cycle symbol) of $10.95 \mathrm{kV}$ were within the feeder upper and lower limits $\left(\mathrm{V}_{\text {f-upper }}\right.$ of $11.66 \mathrm{kV}$ and $\mathrm{V}_{\text {f-lower }}$ of $\left.10.34 \mathrm{kV}\right)$. The $\mathrm{DG}$ started to output power at t1 (2.2s). When the DG power reached to $800 \mathrm{~kW}$ at $\mathrm{t}_{2}(5.6 \mathrm{~s}), \mathrm{V}_{\mathrm{DG}}$ exceeded $\mathrm{V}_{\mathrm{DG} \text {-upper }}$ of $11.22 \mathrm{kV}$. As $\mathrm{V}_{\mathrm{S}}$ remained unchanged, the AVC relay did not send a tap changing command to the OLTC transformer. However as the AVRS algorithm detected $\mathrm{V}_{\mathrm{DG}}$ exceeding $\mathrm{V}_{\mathrm{DG}}$ upper at $t_{2}$ it waited $4 \mathrm{~s}$ a pre-set time delay. At $t_{3}(9.6 \mathrm{~s})$ the AVRS algorithm changed the AVC relay voltage reference from $11.165 \mathrm{kV}$ to $10.89 \mathrm{kV}$ and the AVC relay sent the tap changing command to the OLTC transformer. This resulted in the change of $\mathrm{Vs}$ from 10.97 to $10.92 \mathrm{kV}, \mathrm{V}_{\mathrm{DG}}$ from $11.22 \mathrm{kV}$ to $10.98 \mathrm{kV}$ and $\mathrm{V} 6$ from $10.95 \mathrm{kV}$ to $10.88 \mathrm{kV}$. As $\mathrm{V}_{\mathrm{DG}}$ of $10.98 \mathrm{kV}$ was below $\mathrm{V}_{\mathrm{DG} \text {-upper, }}$, the $\mathrm{DG}$ was thus allowed to increase more power from $800 \mathrm{~kW}$ to $1600 \mathrm{~kW}$ at $\mathrm{t} 4(13.2 \mathrm{~s})$. When the DG power reached $1600 \mathrm{~kW}, \mathrm{~V}_{\mathrm{DG}}$ exceeded $\mathrm{V}_{\mathrm{DG} \text {-upper }}$ again. The AVRS algorithm waited $4 \mathrm{~s}$ and then changed $V_{\text {ref }}$ from $10.89 \mathrm{kV}$ to $10.615 \mathrm{kV}$. The AVC waited $4 \mathrm{~s}$ and then instructed the OLTC transformer to tap down. This brought $\mathrm{Vs}$ from $10.92 \mathrm{kV}$ to $10.69 \mathrm{kV}$ and $\mathrm{V}_{\mathrm{DG}}$ from $11.22 \mathrm{kV}$ to $10.98 \mathrm{kV}$ at $\mathrm{t}_{5}(17.2 \mathrm{~s})$.

In summary, results obtained from the simulations show that the AVRS algorithm can be used to set $\mathrm{V}_{\text {ref }}$ for an AVC relay to increase the DG power output under both minimum and maximum load conditions. Comparing the DG power between Fig.7 and Fig.9, it may be seen that in this case the DG power under the minimum load condition can export more power than with maximum load condition due to a smaller voltage difference between $V_{D G}$ and $V_{6}$ under the minimum load conditions.

\section{IV- Prototype AVRS Device and RTDS Testing facility}

The AVRS algorithm was implemented on a Hathaway RMS900 Distribution Automation (DA) controller. To test this RMS900 prototype AVRS device, a closed-loop Real Time Digital Simulator (RTDS) hardware testing facility was constructed as shown in Fig.10. 


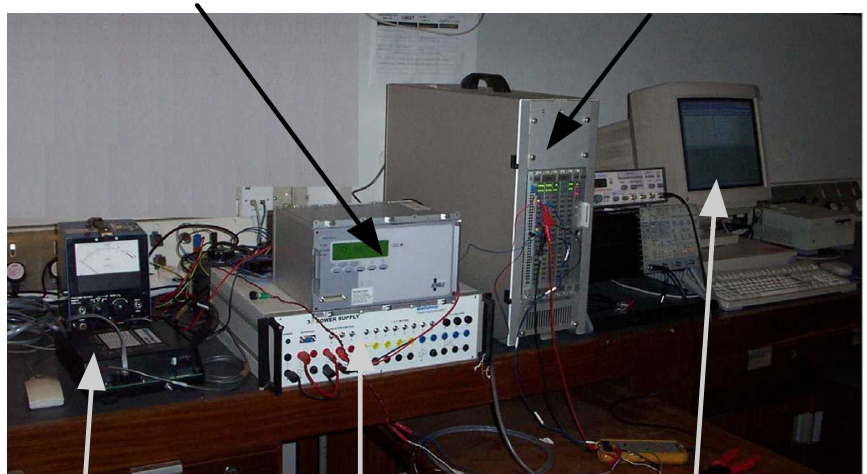

AVRS device Voltage amplifier

Workstation

Fig. 10 RTDS based a closed-loop testing facility

This facility consists of a workstation, RTDS equipment, MicroTAPP AVC relay [3], a voltage amplifier and the RMS900 prototype AVRS device. The workstation and the RTDS equipment were used to simulate the same model as that in Fig.5. The RTDS equipment stored the RTDS simulated model and ran it in real time. The connection of the RTDS equipment, the MicroTAPP relay, the voltage amplifier and the RMS900 prototype AVRS device is shown in Fig.11.

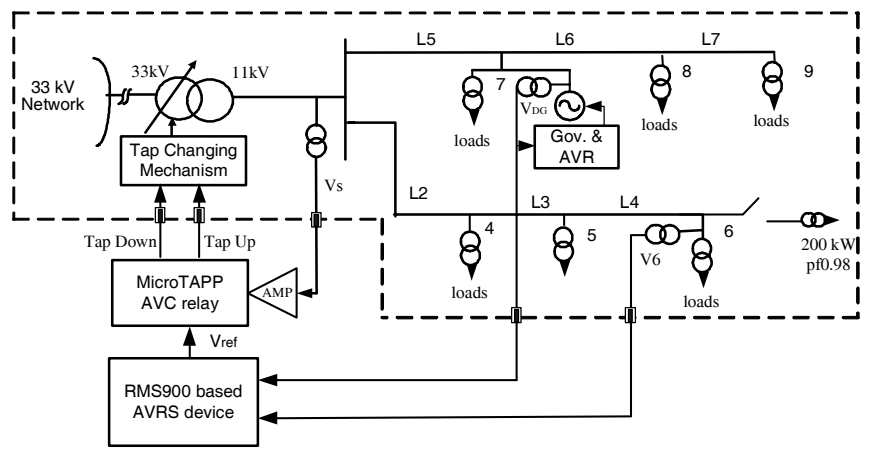

Fig. 11 The connection of the RTDS feeder model and the RMS900 prototype AVRS device

The simulated RTDS feeder model included the same $33 \mathrm{kV}$ network source model, the OLTC transformer model and the DG model as that in Fig.5. Since the used RTDS equipment had a limited capacity to simulate large network nodes, the RTDS model only simulated two critical feeders (one connected to the DG and the other connected to the largest load centre 6).

The MicroTAPP AVC relay measured Vs of the RTDS model. As the input of the MicroTAPP AVC relay was 110V, the voltage amplifier was used to convert Vs at the RTDS equipment $\mathrm{D} / \mathrm{A}$ output of $\pm 5 \mathrm{~V}$ to $110 \mathrm{~V}$. The MicroTAPP relay allows four voltage reference settings, $\mathrm{V}_{\text {ref }}$, to be selected. The initial time and inter-tap delays of the MciroTapp were set at 22s and 10s. The time delay of the AVRS device was set at 20s.

\section{Cases studies}

Similar to the EMTDC off-line simulation, only three essential voltage measurements on the network of Fig. 11 were considered. Since the RMS900 prototype AVRS device was configured to measure phase voltages, three critical phase voltages, $\mathrm{V}_{\mathrm{S}-\mathrm{ph}}$ at the busbar sending end, $\mathrm{V}_{\mathrm{DG}-\mathrm{ph}}$ at the $\mathrm{DG}$ site, and $V_{6-p h}$ at load centre 6 were selected. For $11 \mathrm{kV}$ network, the feeder phase voltage upper limit is $6.73 \mathrm{kV}$; the feeder phase voltage lower limit is $5.97 \mathrm{kV}$; the DG connection point phase voltage upper limit is $6.48 \mathrm{kV}$ and the phase voltage lower limit is $5.97 \mathrm{kV}$.

As it can be seen from Fig.11, the MicroTAPP relay measured $\mathrm{V}_{\mathrm{S} \text {-ph }}$ and the RMS900 prototype AVRS device measured $\mathrm{V}_{\text {DG-ph }}$ and $\mathrm{V}_{6 \text {-ph. }}$. The measured phase voltages were monitored by an oscilloscope. The scale of the oscilloscope was set at $1.0 \mathrm{~V} / \mathrm{div}(1.0 \mathrm{kV} / \mathrm{div}$ in the RTDS model). The trace time of the oscilloscope was set at 10s/div. When the RMS900 AVRS device detected that either $\mathrm{V}_{\text {DG-ph }}$ or $\mathrm{V}_{6 \text {-ph }}$ were outside the feeder voltage limits, it calculated a new $V_{\text {ref }}$ for the MicroTAPP relay. By changing the DG output or the loads in the RTDS feeder model, the AVRS algorithm in the RMS900 prototype AVRS device was tested in real time.

\section{Increasing levels of the generator output}

This is the case that the minimum loads in load centre 4 to 8 were considered (see Appendix). Initially $\mathrm{V}_{\text {ref }}$ of the AVRS device was set at the phase voltage target 0 of $6.67 \mathrm{kV}$, and the DG outputs were set at zero. The DG increased power output from $0 \mathrm{~kW}$ to $420 \mathrm{~kW}$ or from $420 \mathrm{~kW}$ to $680 \mathrm{~kW}$ in a step function. The feeder voltage profiles under various DG power outputs are shown in Fig.12.

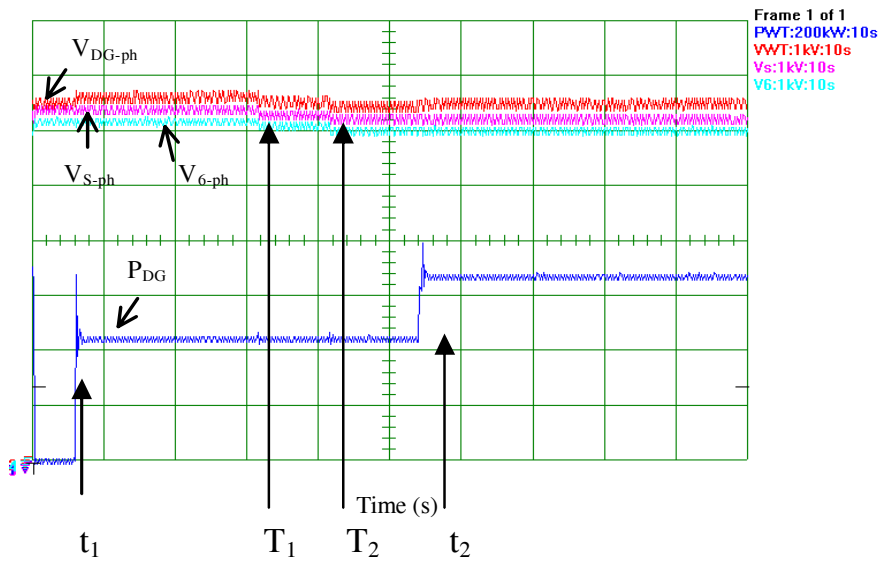

Fig.12 The feeder voltage profile changing as the various DG outputs

Fig.12 shows that under no DG output between $0 \mathrm{~s}$ and $\mathrm{t}_{1}$ $(6 \mathrm{~s}), \mathrm{V}_{\mathrm{S}-\mathrm{ph}}$ of $6.35 \mathrm{kV}$ was within the MicroTAPP relay deadband limits; $\mathrm{V}_{\mathrm{DG}-\mathrm{ph}}$ of $6.33 \mathrm{kV}$ was within the $\mathrm{DG}$ connection point phase voltage limits, and $\mathrm{V}_{6-\mathrm{ph}}$ of $6.20 \mathrm{kV}$ were within the feeder limits. At $t_{1}(2 s)$, the DG power was increased from $0 \mathrm{~kW}$ to $420 \mathrm{~kW}$. This caused $\mathrm{V}_{\text {DG-ph }}$ to rise to $6.67 \mathrm{kV}$, but $\mathrm{V}_{\mathrm{S} \text {-ph }}$ and $\mathrm{V}_{6 \text {-ph }}$ remained barely changed. As $\mathrm{V}_{\mathrm{S} \text {-ph }}$ of $6.35 \mathrm{kV}$ was within the MicroTAPP relay deadband limits, it took no action. However when the RMS900 AVRS device detected $\mathrm{V}_{\text {DG-ph }}$ of $6.67 \mathrm{kV}$, which exceeded the DG connect point phase voltage upper limit of $6.48 \mathrm{kVat} \mathrm{t}_{1}$, it waited $22 \mathrm{~s}$ initial delay time. At $T_{1}(30.4 \mathrm{~s})$, the RMS900 AVRS device $\mathrm{V}_{\text {ref }}$ from target 0 of $6.45 \mathrm{kV}$ to target 1 of $6.29 \mathrm{kV}$, and the MicroTAPP relay instructed the RTDS OLTC transformer model to change one tap down at $\mathrm{T} 1$ (30.4s). This brought $\mathrm{V}_{\mathrm{S} \text { - }}$ ph down from $6.46 \mathrm{kV}$ to $6.37 \mathrm{kV}$. Since $\mathrm{V}_{\mathrm{S}-\mathrm{ph}}$ of $6.37 \mathrm{kV}$ was still outside of the MicroTAPP relay deadband, the MicroTapp relay waited 10 s of inter-tap delay and then instructed the RTDS OLTC transformer model to change 
another tap down at $\mathrm{T}_{2}(40.3 \mathrm{~s}) . \mathrm{V}_{\mathrm{S} \text {-ph }}$ was thus changed from $6.367 \mathrm{kV}$ to $6.293 \mathrm{kV}$ and $\mathrm{V}_{\mathrm{DG}-\mathrm{ph}}$ from $6.44 \mathrm{kV}$ to $6.33 \mathrm{kV}$. Since $\mathrm{V}_{\mathrm{DG}-\mathrm{ph}}$ of $6.33 \mathrm{kV}$ at $\mathrm{T}_{2}$ was lower than the $\mathrm{DG}$ connection point phase voltage upper limit, the DG was thus allowed to output increasing power from $420 \mathrm{~kW}$ at $\mathrm{t}_{1}$ to $680 \mathrm{~kW}$ at $\mathrm{t}_{2}$ (55s). At $t_{2}(25 \mathrm{~s}) \mathrm{V}_{\text {DG-ph }}, \mathrm{V}_{\mathrm{S} \text {-ph }}$ and $\mathrm{V}_{6 \text {-ph }}$ were slightly raised and they were all within the DG connection point phase voltage upper limit and the feeder phase voltage limits.

By comparing the RTDS testing results of phase voltages in Fig.12 with the EMTDC offline simulation results of line-toline voltages in Fig.7, similar voltage levels and two tap changes were observed during the first power raise from zero to $430 \mathrm{~kW}$. However after two tap changes, the RTDS loop testing allowed an increase in DG power that was smaller than in the EMTDC off-line simulation. This was because the actual voltage measurement contained RMS voltage ripples, which were measured by the RMS900 device in the RTDS loop test.

Further RTDS loop tests were conducted. The tests included connecting minimum load condition, or disconnecting the DG from the network, or connecting extra load to load centre 6 . All the tests confirmed that the algorithm in the RMS900 prototype AVRS device had performed correctly.

\section{V- CONCLUSIONS}

An AVRS technique, acting to change the voltage reference for existing AVC relays, has been presented. The technique has not only been simulated on the EMTDC simulator, but has also been implemented on a RMS900 prototype AVRS device. A realistic multiple feeder distribution network supplied from the same transformer was selected. By adding the load uncertainty errors up to $\pm 50 \%$ on the given maximum and minimum load conditions, load flow studies was conducted to identify ' $m$ ' essential remote measurement points on the network. Both EMTDC evaluation and RTDS tests were performed under the changes of DG power output and various load conditions. Results show that the technique performed correctly. They also show that by only using the MicroTAPP relays, the capacity of DG that may be connected to a distribution feeder without causing over-voltage is limited. The results described in the paper show that the use of the prototype AVRS device can increase the DG that may be connected to multiple feeders. It is believed that the AVRS technique, acting on tap changing control of the transformer supplying the feeder, gives power utilities an economic option to automatically set $\mathrm{V}_{\text {ref }}$ for many already installed AVC relays and to achieve increased DG connection to distribution networks.

\section{VII - REFERENCES}

[1] N. Jenkins, R. Allan, P. Corssley, D. Kirschen, and G. Strbac, "Embedded Generation", IEE Power and Energy Publication Series, 21, 2000.

[2] H. Leite and H. Y. Li, "Effect of Distributed Generation on Distribution Network Voltage Regulation", Euro Conference on Risk Management Applied to Power Systems in Market Environment, RMAPS 2001, Porto, September 2001.
[3] VATech publicaion, "MicroTAPP \& SuperTAPP - Automatic Voltage Control Relay", VA Tech ELIN Group T\&D Reyrolle ACP Ltd Protection, 1999.

[4] M. S. Calovic, "Modelling and Analysis of Under Load Tap Changing Transformer Control Systems", IEEE Transactions on Power Apparatus and Systems, Vol. PAS-103, No. 7, July 1984, pp 1909-1915.

[5] Q. Wu, D. H. Popovic, D. J. Hill and M. Larsson, "Tap Changing Dynamic Models for Power System Voltage Behaviour Analysis", Proc. of $13^{\text {th }}$ Power System Computation Conference (PSCC), Trondheim, Norway, July 1999.

[6] M. Thomson, "Automatic Voltage Control Relays and Embedded Generation", pp.71 - 99, Power Engineering Journal, April 2000

[7] H. Kirkham, R. Das, "Effects of Voltage Control in Utility Interactive Dispersed Storage and Generation Systems", IEEE Transaction on Power Apparatus and Systems, Vol. PAS-103, No.8, August 1984, pp.2277-2282,

[8] Joon-Ho Choi and Jae-Chul Kim, "Advanced Voltage Regulation Method at the Power Distribution System Interconnected with Dispersed Storage And Generation System" IEEE Transactions on Power Delivery, Vol. 15, April 2000, pp691-696.

[9] S. Persaud, B. Fox and D. Flynn, "The effects of Distributed Generation on Automatic Voltage Control in Radial Distribution Networks" $34^{\text {th }}$ Universities Power Engineering Conference, UPEC '99, Leicester, UK, September 1999, pp365 - 368.

[10] M.. E. Baran and Ming-Yung Hsu, "Volt/Var Control at Distribution Substations" IEEE Transactions on Power Systems, Vol.14, No 1, February 1988, pp312-318.

[11] G Stebac, N. Jenkins, J Mutale, N. Hatziargyriou, T. Karakatsanis, P. Ioannidou, C. Cokkinelis and M. Davidson, "Electricity Tariffs and Embedded Renewable Generation", The final report, the European Commission funded project JOR3CT98-0201, September 2000.

[12] DTI publication, "The electricity safety, quality and continuity regulations 2002", ISBN 0-11-042920-6, Statuary Instruments, No 2665, 2002.

\section{VIII - BIOGRAPHIES}

H H.Y. Li (M'99) received Ph.D. degree from the University of Bath, U.K., in 1994. Currently he is a Lecturer in the School of Electrical and Electronics Engineering, The University of Manchester (formerly UMIST). His research interests are power system automation and information systems, including power system communications, protection, distributed generation integration, HV optical sensors and signal processing. He is a Member of IEEE and IEE.

H. Leite received BSc degree in Electrical Engineering from University of Porto, Portugal in 2000 and the $\mathrm{PhD}$ degree in Electrical Engineering from The University of Manchester, UK in 2004. Helder Leite joined University of Porto, Portugal as a Lecturer in 2005. His research interests include Distribution Generation, Electric Power Systems and Power Systems Protection.

\section{VIV Appendix}

Table A1 Line impedance of L1 to L9 in Fig.5

\begin{tabular}{|l|l|l|l|l|l|}
\hline Line & L1 & L2 & L3 & L4 & L5 \\
\hline$\Omega$ & $13+\mathrm{j} 1.0$ & $4.1+\mathrm{j} 1.0$ & $4.1+\mathrm{j} 1.0$ & $11.1+\mathrm{j} 4.9$ & $2.2+\mathrm{j} 1.3$ \\
\hline & & & & & \\
\hline Line & L6 & L7 & L8 & L9 & \\
\hline$\Omega$ & $11.1+\mathrm{j} 4.9$ & $5.8+\mathrm{j} 2.6$ & $0.4+\mathrm{j} 0.12$ & $2.2+\mathrm{j} 1.7$ & \\
\hline
\end{tabular}

TableA2 Load conditions of load centre 2 to 11 in Fig.5

\begin{tabular}{|l|l|l|l|l|l|}
\hline Load centres & $\mathbf{2}$ & $\mathbf{3}$ & $\mathbf{4}$ & $\mathbf{5}$ & $\mathbf{6}$ \\
\hline Min $(\mathrm{kVA} / \mathrm{pf} 0.98)$ & 5.1 & 55.1 & 8.2 & 70.4 & 5.1 \\
\hline Max (kVA/pf 0.98) & 4.7 & 220.4 & 33.7 & 280.6 & 55.1 \\
\hline & & & & & \\
\hline Load centres & $\mathbf{7}$ & $\mathbf{8}$ & $\mathbf{9}$ & $\mathbf{1 0}$ & $\mathbf{1 1}$ \\
\hline Min $(\mathrm{kVA} / \mathrm{pf} 0.98)$ & 55.1 & 25.6 & 9.2 & 10.2 & 9.2 \\
\hline
\end{tabular}




\begin{tabular}{|l|l|l|l|l|l|}
\hline Max (kVA / pf 0.98 ) & 220.4 & 104.1 & 35.7 & 41.8 & 36.7 \\
\hline
\end{tabular}

where $\mathrm{pf}$ is defined as power factor. 